\title{
The application of genetics and nutritional genomics in practice: an international survey of knowledge, involvement and confidence among dietitians in the US, Australia and the UK
}

\author{
Jorja Collins • Brenda Bertrand • Veronica Hayes • \\ Sherly X. Li • Jane Thomas $\cdot$ Helen Truby • \\ Kevin Whelan
}

Received: 23 April 2013/Accepted: 18 June 2013/Published online: 17 July 2013

(c) Springer-Verlag Berlin Heidelberg 2013

\begin{abstract}
As a result of expanding scientific understanding of the interplay between genetics and dietary risk factors, those involved in nutritional management need to understand genetics and nutritional genomics in order to inform management of individuals and groups. The aim of this study was to measure and determine factors affecting dietitians' knowledge, involvement and confidence in genetics and nutritional genomics across the US, Australia and the UK. A cross-sectional study was undertaken using an online questionnaire that measured knowledge and current involvement and confidence in genetics and nutritional genomics. The questionnaire was distributed to dietitians in the US, Australia and the UK using email lists from the relevant professional associations. Data were collected from 1,844 dietitians who had practiced in the previous 6 months. The main outcomes were knowledge of genetics and nutritional genomics and involvement and confidence in undertaking clinical and educational activities related to genetics and nutritional genomics. Mean scores for knowledge, involvement and confidence were calculated. Analysis of variance and $\chi^{2}$ analysis were used to compare scores and frequencies. Multivariate linear regression was
\end{abstract}

J. Collins $\cdot$ S. X. Li $\cdot$ H. Truby $(\bowtie)$

Department of Nutrition and Dietetics, Monash University,

Level 1264 Ferntree Gully Road, Notting Hill,

VIC 3168, Australia

e-mail: helen.truby@monash.edu

B. Bertrand · V. Hayes

Department of Nutrition Science, East Carolina University,

116 Rivers Building, Greenville, NC 252-328-5364, USA

J. Thomas $\cdot$ K. Whelan

Diabetes and Nutritional Sciences Division, School of Medicine,

King's College London, 150 Stamford Street,

London SE1 9NH, UK used to determine predictors of high scores. The results demonstrated significant differences in involvement $(p<0.001)$ and confidence $(p<0.001)$ but not knowledge scores $(p=0.119)$ between countries. Overall, dietitians reported low levels of knowledge (mean knowledge score $56.3 \%$ ), involvement (mean number of activities undertaken 20.0-22.7 \%) and confidence (mean confidence score 25.8-29.7\%). Significant relationships between confidence, involvement and knowledge were observed. Variables relating to education, experience, sector of employment and attitudes were also significantly associated with knowledge, involvement and confidence. Dietitians' knowledge, involvement and confidence relating to genetics and nutritional genomics remain low and further investigation into factors contributing to this is required.

Keywords International $\cdot$ Nutrigenetics $\cdot$ Nutrigenomics · Dietitian

\section{Introduction}

The Human Genome Project has precipitated remarkable advances in our understanding of the genetic associations of a range of diseases (Wellcome Trust Case Consortium 2007). Greater understanding about individualised responses to environmental factors such as drugs and nutrients due to genetic variation has resulted in the emerging disciplines of pharmacogenomics and nutritional genomics. Nutritional genomics considers how nutrients or dietary constituents influence gene expression (nutrigenomics) and how genetic variation influences metabolic response to nutrients or dietary constituents (nutrigenetics) (McCarthy et al. 2008), thus potentiating dietary interventions that are personalised to a patient's genomic 
profile. Translating this science to practice is crucial to ensure the potential benefits for disease prevention and management are realised. In view of the established and emerging role for genetics and nutritional genomics in health care, there is impetus to provide a genetics-led health service in many countries (DH 2008; NCHPEG 2001).

In 2001, Guttmacher et al. described how genomicsbased medicine would trend towards delivery by nongenetics specialists who 'bring different knowledge bases, talents and emphases to genetic care' (Guttmacher et al. 2001). The successful application of nutritional genomics necessitates cohesive action from multiple professionals from different fields working across the spectrum from 'bench to bed' in research, education and healthcare environments. Previous research has addressed the opportunities and barriers relating to genetics and genomics among various workforces including public health, medicine, primary care, nursing, pharmacy, occupational therapy and dietetics (Chen and Goodson 2007; Emery et al. 1999; Kirk et al. 2008; Ferro et al. 2012; Kyler and Thomas 2000; DeBusk et al. 2005). One group of health professionals who will be involved in the application of nutritional genomics are dietitians, who have expertise in biomedical and nutritional sciences and are well positioned to translate and deliver health messages to the public.

The current role of the dietetic profession in the application of genetics and nutritional genomics has not been extensively investigated. A study in the United States (US) interviewed 2,052 health professionals, of whom 372 were dietitians, and found variation in genetics service provision, genetics education and a desire for continuing professional development in this area (Lapham et al. 2000; Gilbride and Camp 2004). In a study of 390 dietitians in the United Kingdom (UK), involvement, confidence and knowledge of genetics and nutrigenomics were generally low (Whelan et al. 2008). In both of these studies, dietitians with more genetics education had greater confidence and knowledge (McCarthy et al. 2008; Lapham et al. 2000; Gilbride and Camp 2004). Limited knowledge and confidence about genetics and nutritional genomics is likely to be a major barrier preventing the application of these concepts (Rosen et al. 2006).

As the science of genetics and nutritional genomics is advancing at a rapid pace and impacting profoundly on how disease is prevented and managed, health professionals including dietitians need to embrace and integrate nutritional genomics into their practice. The aim of this study was to measure and investigate factors associated with knowledge, involvement and confidence in genetics and nutritional genomics among an international sample of dietitians in the US, Australia and the UK.

\section{Methods}

Study design

This international cross-sectional study investigated dietitians' knowledge, involvement and confidence in genetics and nutritional genomics. The study was approved by the institutional review boards of East Carolina University (US), Monash University (Australia) and King's College London (UK). Informed consent was obtained from all participants, and data were collected anonymously.

\section{Questionnaire}

The questionnaire was developed using a previously validated survey instrument (McCarthy et al. 2008; Whelan et al. 2008) and refined using the results of seven focus groups conducted with clinical $(n=12)$, academic $(n=16)$ and newly graduated $(n=6)$ dietitians. The focus groups ensured that the questionnaire addressed contemporary issues in genetics and nutritional genomics in international practice, and covered preparedness, perceived opportunities, benefits and barriers of nutritional genomics in dietetics. Once refined, face validity and online usability were determined through a pilot survey of 16 dietitians, and minor modifications were made based upon feedback, adapted by language and context of practice for each country and then administered online.

The final questionnaire included four sections surveying (1) knowledge; (2) confidence; (3) involvement and (4) demographics. The knowledge section had 16 multiple choice questions measuring knowledge of basic terminology and concepts relating to genetics (12 questions; 1-12) and nutritional genomics (4 questions; 13-16) (Table 1). The involvement and confidence sections related to a series of 11 clinical and 3 educational activities about genetics and nutritional genomics (Table 2). The genetics activities were taken from the clinical and educational activities included in the HuGEM study (Lapham et al. 2000) and were only collected from respondents who worked in the clinical or educational sector for a substantial amount of time. Involvement in each activity was measured using a dichotomous response set (involved, not involved), and confidence was measured using a 5-point Likert scale $(0$ 'very low confidence' to 4 'very high confidence'). The demographic section surveyed dietetic employment, qualifications and experience.

\section{Participants}

Registered Dietitians who had practiced in the US, Australia or UK in the last 6 months were eligible to participate. To ensure relevance to the widest context of dietetics, 
Table 1 Correct responses to questions to measure dietitians' knowledge of genetics and nutritional genomics [ $n(\%)]$

\begin{tabular}{|c|c|c|c|c|c|}
\hline \multicolumn{2}{|c|}{ Multiple choice questions } & \multirow{2}{*}{$\begin{array}{l}\text { Overall } \\
n=1844 \\
1560(84.6)\end{array}$} & \multirow{2}{*}{$\begin{array}{l}\text { US } \\
n=461 \\
391(84.8)\end{array}$} & \multirow{2}{*}{$\begin{array}{l}\text { Australia } \\
n=390\end{array}$} & \multirow{2}{*}{$\begin{array}{l}\text { UK } \\
n=993\end{array}$} \\
\hline 1 & A 'gene' is? & & & & \\
\hline 2 & A 'chromosome' is? & $1661(90.1)$ & $422(91.5)$ & $345(88.5)$ & $894(90.0)$ \\
\hline 3 & An 'allele' is? & $796(43.2)$ & $159(34.5)$ & 194 (49.7) & $443(44.6)$ \\
\hline 4 & 'Genotype' is? & $1330(72.1)$ & 307 (66.6) & $288(73.8)$ & $735(74.0)$ \\
\hline 5 & 'Phenotype' is? & $1173(63.6)$ & $260(56.4)$ & $268(68.7)$ & $645(65.0)$ \\
\hline 6 & A 'polymorphism' is? & $733(39.8)$ & $174(37.7)$ & $156(40.0)$ & $403(40.6)$ \\
\hline 7 & A 'mutation' is? & 1399 (75.9) & $334(72.5)$ & $314(80.5)$ & $751(75.6)$ \\
\hline 8 & 'PCR' means? & $850(46.1)$ & $176(38.2)$ & $231(59.2)$ & $443(44.6)$ \\
\hline 9 & What condition is not associated with the MTHFR $677 \mathrm{C} \rightarrow \mathrm{T}$ defect? & $346(18.8)$ & $104(22.6)$ & $55(14.1)$ & $187(18.8)$ \\
\hline 10 & Which of the following is not a multi-factorial disease? & $1039(56.3)$ & $226(49.0)$ & $207(53.1)$ & $606(61.0)$ \\
\hline 11 & Which of the following statements about genetic defects/disorders is false? & $1131(61.3)$ & $313(67.9)$ & $241(61.8)$ & $577(58.1)$ \\
\hline 12 & In which condition is a genetic test regularly used? & $1652(89.6)$ & $393(85.2)$ & $353(90.5)$ & $906(91.2)$ \\
\hline 13 & 'Nutrigenetics' is? & $600(32.5)$ & $163(35.4)$ & 139 (35.6) & $298(30.0)$ \\
\hline 14 & 'Nutrigenomics' is? & $618(33.5)$ & $198(43.0)$ & $131(33.6)$ & $289(29.1)$ \\
\hline 15 & Which of the following applications is not part of nutritional genomics? & $1262(68.4)$ & $343(74.4)$ & $259(66.4)$ & $660(66.5)$ \\
\hline 16 & $\begin{array}{l}\text { Which of the following defects interacts with dietary fat intake to influence the } \\
\text { risk of CVD? }\end{array}$ & $457(24.8)$ & $140(30.4)$ & $92(23.6)$ & $225(22.7)$ \\
\hline
\end{tabular}

Adapted from McCarthy et al. (2008) and Whelan et al. (2008)

all domains of practice were eligible (e.g. clinical, public health, education and industry). Exclusion criteria were nutritionists, registered dietetic technicians, dietetic assistants and student dietitians.

\section{Recruitment}

Participants were recruited through the "Find A Dietitian" search function on the Academy of Nutrition and Dietetics (AND) website and through the membership database of the national professional bodies in Australia (Dietitians Association of Australia, DAA) and the UK (British Dietetic Association, BDA). All registered dietitians listed on the AND website $(n=4,066)$, and all members of the DAA $(n=4,720)$ and the BDA $(n=5,500)$ where email addresses were available (total of 14,286 dietitians) were invited to participate. Potential participants received an invitation email with a weblink to the online survey (Survey Monkey ${ }^{\circledR}$, Palo Alto, California, US, research version licensed to Monash Nutrition and Dietetics). There are a number of advantages of survey distribution via the Internet, notably including global reach, ease and timeliness of follow-up, low administration cost and burden and convenience for responders (Evans and Mathur 2005). In order to maximise response rate, reminder emails were sent to all potential participants after $1-2$ weeks and an incentive to win small gift vouchers was offered to participants in the UK and Australia but not in the US (Edwards et al. 2009).
Statistical analyses

Statistical analysis was performed using SPSS version 17.0 (SPSS Inc., Chicago, Illinois). Mean (SD) scores were calculated for knowledge, involvement and confidence in clinical and educational activities. Knowledge scores were calculated as the percentage of correct answers for the genetics section, the nutritional genomics section and in total. An involvement score was calculated from the sum of clinical or educational activities undertaken in the last 6 months, while confidence scores were determined from the sum of confidence levels ( 0 'very low confidence' to 4 'very high confidence') for each activity, and this was presented as percentage of total possible scores for clinical or educational activities, respectively.

One-way analysis of variance (ANOVA) with Bonferroni post hoc correction was used to compare knowledge, involvement and confidence scores between countries. $\chi^{2}$ analysis was used to compare the $n(\%)$ of dietitians involved in educational and clinical activities between countries.

Multiple linear regression was used to explore the associations between high scores for knowledge, involvement and confidence and their predictor variables. Univariate analysis was initially undertaken to identify relevant factors. These factors related to education (postgraduate dietetics qualification, having a $\mathrm{PhD}$ ), practice (years of experience, sector of dietetics, e.g. clinical, public 


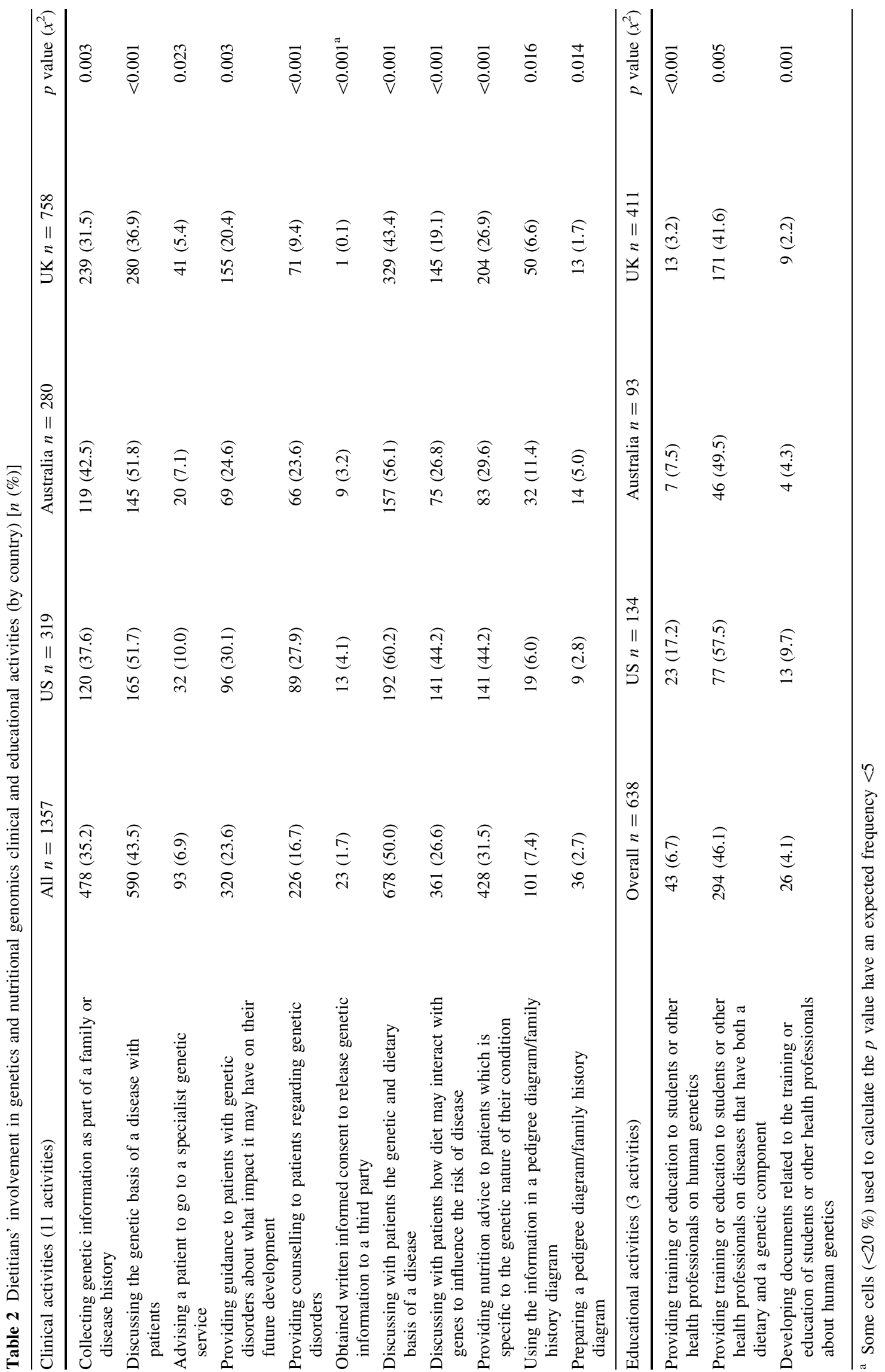


health) and attitudes (perceived importance of genetics). Knowledge, involvement and confidence scores were also included as independent variables as appropriate. Years of experience and scores were entered as continuous data, and all other variables were dichotomous. Those that were statistically significant $(p<0.05)$ on univariate analysis were entered into multivariate linear regression models. Five regression models were developed to investigate each outcome (knowledge, involvement in clinical activities, involvement in educational activities, confidence in clinical activities and confidence in educational activities).

Preliminary analyses were conducted to assess the data's compliance with assumptions. The dependent variables were non-normally distributed; however, logistic regression could not be undertaken due to small groups and extensive exclusion of cases with incomplete data. The majority of independent variables did not show a strong association with the dependent variables $(r<0.3)$ with the notable exception of a high correlation between clinical and education confidence scores $(r=0.737)$. Nevertheless, there was no evidence of multicollinearity, supported by tolerance and variance inflation factor (VIF) results within normal limits. Outliers existed but these cases remained in the analysis as there was no overall effect on the model with the maximum value of Cook's distance $<1.0$. Exp (B) and the $95 \%$ confidence interval (CI) were reported for linear models to identify the strength, direction and significance of the association. $p$ values of $<0.05$ was considered statistically significant.

\section{Results}

Of the 14,286 questionnaires distributed, 2,287 were accessed (actual response rate $16 \%$ ) by $568(14 \%)$ of dietitians in the US, $507(11 \%)$ in Australia and 1212 $(22 \%)$ in the UK. Among these participants, 179 did not consent or meet the inclusion criteria and 264 withdrew before commencement. Of the remaining 1,844 (valid response rate $13 \%$ ) who submitted a questionnaire and on whom data were analysed, $461(25 \%)$ were from the US, 390 (21\%) from Australia and 993 (54 \%) from the UK. A further 158 responses were incomplete.

\section{Demographic characteristics}

The majority of respondents worked in clinical dietetics, had a bachelor- or masters-level degree and had worked as a dietitian for an average of 13.3 (10.6, SD) years (Table 3). There were statistically significant differences between countries for some demographic characteristics including years of experience and highest degree (all $p<0.001$ ) (Table 3).
Knowledge

Dietitians answered approximately half the questions correctly, with the percentage of correct responses ranging substantially between questions (Table 1). There was no differences between countries in total knowledge scores (Table 4). The multivariate model containing 14 predictor variables was statistically significant, although it explained only $13.9 \%$ of the variance of high knowledge scores $\left(r^{2}=0.139, F(14,492)=5.657, p<0.001\right) \quad($ Table 5). The strongest predictor of high knowledge scores was confidence in undertaking educational activities in genetics and nutritional genomics $\quad(\beta=0.26, \quad 95 \%$ $\mathrm{CI}=0.13-0.45)$. Knowledge scores were the highest among those with fewer years of experience and those who perceived an understanding of genetics to be important (Table 5).

\section{Involvement}

The majority of respondents who reported working in clinical dietetics $(n=1,357)$ or education $(n=638)$ lacked involvement in clinical and educational activities relating to genetics and nutritional genomics (Table 2). Of the 11 clinical activities, on average, dietitians were involved in 2.5 (2.3, SD), and of the three educational activities, educators were involved in $0.6(0.7, \mathrm{SD})$ (Table 4). At most, $50 \%$ of clinical dietitians had 'discussed with patients the genetic and dietary basis of a disease,' while $46.1 \%$ of educators had 'provided training or education to students or other health professionals on diseases that have both a dietary and genetic component' (Table 2). Multivariate models predicted $40 \%$ of the variance associated with high involvement scores for clinical activities $\left(r^{2}=0.397\right.$, $F(13,493)=24.971, p<0.001)$ and $42 \%$ for educational activities $\left(r^{2}=0.423, \quad F \quad(11,495)=33.053\right.$, $p<0.001$ ) (Table 6). The strongest predictor of high involvement for both clinical and educational activities was high confidence.

\section{Confidence}

The majority of clinical dietitians and educators reported low confidence in clinical and educational activities relating to genetics and nutritional genomics (Table 4). Respondents were most confident in their ability to 'discuss with patients the genetic and dietary basis of a disease' (54.6\% reporting moderate/high confidence) (not shown). Approximately $66 \%$ of the variance associated with high confidence for clinical activities $\left(r^{2}=0.655\right.$, $F(15,491)=62.151, p<0.001)$ and $68 \%$ for educational activities $\left(r^{2}=0.677, F(12,494)=86.429, p<0.001\right)$ 
Table 3 Demographic characteristics of respondents $[n, \%]$

\begin{tabular}{|c|c|c|c|c|}
\hline & All & US & Australia & UK \\
\hline \multicolumn{5}{|c|}{ Sector of dietetics where respondents worked for a substantial amount of time } \\
\hline & $n=2669^{\mathrm{a}}$ & $n=415$ & $n=367$ & $n=904$ \\
\hline Clinical dietetics & $1394(82.7)$ & $331(79.8)$ & $302(82.3)$ & $761(84.2)$ \\
\hline $\begin{array}{l}\text { Educating students or other health } \\
\text { professionals }\end{array}$ & $533(31.6)$ & $113(27.2)$ & $76(20.7)$ & $344(38.1)$ \\
\hline Research & $169(10.0)$ & $26(6.3)$ & $57(15.5)$ & $86(9.5)$ \\
\hline Food service/food industry & $100(5.9)$ & $43(10.4)$ & $34(9.3)$ & $23(2.5)$ \\
\hline Public health/policy & $236(14.0)$ & $56(13.5)$ & $66(18.0)$ & $114(12.6)$ \\
\hline Professional dietetic body/government agency & $35(2.1)$ & $8(1.9)$ & $8(2.2)$ & $19(2.1)$ \\
\hline Managing dietetic services & $161(9.5)$ & $31(7.5)$ & $36(9.8)$ & $94(10.4)$ \\
\hline Media & $41(2.4)$ & $21(5.1)$ & $4(1.1)$ & $16(1.8)$ \\
\hline \multicolumn{5}{|l|}{ Number of years experience as a dietitian } \\
\hline & $n=1686$ & $n=415$ & $n=367$ & $n=904$ \\
\hline $0-2$ & $210(12.5)$ & $15(3.6)$ & $80(21.8)$ & $115(12.7)$ \\
\hline $3-5$ & $312(18.5)$ & $50(12.0)$ & $85(23.2)$ & $117(19.6)$ \\
\hline $6-10$ & $342(20.3)$ & $60(14.5)$ & $80(21.8)$ & $202(22.3)$ \\
\hline $11-20$ & $395(23.4)$ & $93(22.4)$ & $67(18.3)$ & $235(26.0)$ \\
\hline 21 or more & $427(25.3)$ & $197(47.5)$ & $55(15.0)$ & $175(19.4)$ \\
\hline \multicolumn{5}{|l|}{ Highest academic degree } \\
\hline & $n=1686$ & $n=415$ & $n=367$ & $n=904$ \\
\hline Bachelor & $794(47.1)$ & $130(31.3)$ & $179(48.8)$ & $485(53.7)$ \\
\hline Masters & $800(47.4)$ & $252(60.7)$ & $169(46.0)$ & $379(41.9)$ \\
\hline Doctorate & $74(4.4)$ & $24(5.8)$ & $17(4.6)$ & $33(3.7)$ \\
\hline Other qualification & $18(1.1)$ & $9(2.2)$ & $2(0.5)$ & $7(0.8)$ \\
\hline
\end{tabular}

The final regression model was only able to explain a very small amount of the variance in dietitians' knowledge of genetics and nutritional genomics, and there are a number of potential explanations for this. First, the majority of knowledge scores were tightly clustered around $50 \%$, contributing to the inability of the model to find associations. Second, knowledge was measured using multiple choice questions, which although previously validated may not measure the totality of knowledge in this area. Third, some factors that may significantly predict knowledge were not measured here. For example, surveys (McCarthy et al. 2008; Oosthuizen 2011) and an intervention study (Cragun et al. 2005) indicate that knowledge of genetics and nutritional genomics increases with university training or professional development in these areas. However, from the data presented, high levels of confidence in educating others in genetics activities are predictive of high knowledge scores, which reinforces that teaching requires expert knowledge and skills.

Involvement and confidence

Involvement and confidence were considerably higher for clinical tasks such as 'discussing the genetic basis of a disease with patients' than more specialist activities such 
Table 4 Knowledge, involvement and confidence of genetics and nutritional genomics among dietitians, mean (95\% CI)

\begin{tabular}{|c|c|c|c|c|c|}
\hline Knowledge & All $n=1844$ & US $n=461$ & Australia $n=390$ & $\mathrm{UK} n=993$ & $p$ value (ANOVA) \\
\hline Total score, \% (16 qu) & $56.3(55.5-57.1)$ & $55.6(54.0-57.3)$ & $58.0(56.2-59.8)$ & $55.9(54.8-57.1)$ & 0.119 \\
\hline Genetic score, \% (12 qu) & $61.8(60.9-62.6)$ & $58.9(57.2-60.6)^{\mathrm{a}}$ & $64.0(62.2-65.9)^{\mathrm{b}}$ & $62.2(61.0-63.4)^{\mathrm{b}}$ & $<0.001$ \\
\hline Nutritional genomics score, $\%(4 \mathrm{qu})$ & $39.8(38.5-41.1)$ & $45.8(43.2-48.3)^{\mathrm{a}}$ & $39.8(36.9-42.8)^{\mathrm{b}}$ & $37.1(35.3-38.8)^{\mathrm{b}}$ & $<0.001$ \\
\hline Clinical activities (11 activities) & $n=1357$ & $n=319$ & $n=280$ & $n=758$ & $p$ value (ANOVA) \\
\hline Involvement (number of activities) & $2.5(2.3-2.6)$ & $3.2(2.9-3.5)^{\mathrm{a}}$ & $2.8(2.6-3.1)^{\mathrm{a}}$ & $2.0(1.9-2.2)^{\mathrm{b}}$ & $<0.001$ \\
\hline Confidence score, $\%^{\mathrm{d}}$ & $29.7(28.7-30.8)$ & $38.4(36.2-40.7)^{\mathrm{a}}$ & $33.0(30.8-35.3)^{\mathrm{b}}$ & $24.9(23.7-26.1)^{\mathrm{c}}$ & $<0.001$ \\
\hline Educational activities ( 3 activities) & $n=638$ & $n=134$ & $n=93$ & $n=411$ & $p$ value (ANOVA) \\
\hline Involvement (number of activities) & $0.6(0.5-0.6)$ & $0.8(0.7-1.0)^{\mathrm{a}}$ & $0.6(0.5-0.8)^{\mathrm{b}}$ & $0.5(0.4-0.5)^{\mathrm{c}}$ & $<0.001$ \\
\hline Confidence score, $\%^{\mathrm{d}}$ & $25.8(24.1-27.5)$ & $37.4(33.6-41.3)^{\mathrm{a}}$ & $30.4(25.2-35.6)^{\mathrm{b}}$ & $21.0(19.1-22.0)^{\mathrm{c}}$ & $<0.001$ \\
\hline
\end{tabular}

Mean values with different superscripts $\left({ }^{\mathrm{a}, \mathrm{b}, \mathrm{c}}\right.$ ) were statistically significantly different following ANOVA and Bonferroni post hoc correction

d The confidence score was calculated by the sum of confidence ( 0 'very low confidence' to 4 'very high confidence') for each activity, and this was presented as percentage of total possible score for clinical or educational activities. Therefore, $0 \%$ is 'very low confidence' and $100 \%$ is 'very high confidence'

Table 5 Factors associated with high scores for knowledge of genetics and nutritional genomics among dietitians (Model 1)

\begin{tabular}{lcrr}
\hline & $\mathrm{B} \pm \mathrm{SE}(95 \%$ CI for B) & \multicolumn{1}{c}{$\beta$} & $p$ value \\
\hline Years of experience & $-0.04 \pm 0.01(-0.07$ to -0.02$)$ & -0.16 & 0.001 \\
$\mathrm{PhD}$ & $0.45 \pm 0.26(-0.13$ to 2.51$)$ & 0.08 & 0.076 \\
Graduated via a postgraduate degree & $0.45 \pm 0.26(-0.07$ to 0.96$)$ & 0.07 & 0.088 \\
Perceive genetics to be important & $1.56 \pm 0.63(0.32$ to 2.81$)$ & 0.11 & 0.014 \\
Employed by the public health service & $0.20 \pm 0.29(-0.37$ to 0.77$)$ & 0.03 & 0.496 \\
Clinical dietitian & $-0.39 \pm 0.37(-1.11$ to 0.33$)$ & -0.05 & 0.291 \\
Education dietitian & $0.30 \pm 0.27(-0.24$ to 0.84$)$ & 0.05 & 0.280 \\
Research dietitian & $0.07 \pm 0.46(-0.83$ to 0.97$)$ & 0.01 & 0.875 \\
Government dietitian & $0.80 \pm 0.87(-0.91$ to 2.52$)$ & 0.04 & 0.359 \\
Food service/industry dietitian & $0.53 \pm 0.55(-0.54$ to 1.60$)$ & 0.04 & 0.333 \\
Clinical confidence score & $-0.01 \pm 0.02(-0.06$ to 0.04$)$ & -0.04 & 0.599 \\
Education confidence score & $0.29 \pm 0.08(0.13$ to 0.45$)$ & 0.26 & $<0.001$ \\
Clinical involvement score & $0.07 \pm 0.07(-0.07$ to 0.21$)$ & 0.06 & 0.309 \\
Education involvement score & $0.01 \pm 0.23(-0.45$ to 0.47$)$ & 0.00 & 0.956 \\
By multivariate linear regression & & & \\
\hline
\end{tabular}

as 'obtaining written informed consent to release genetic information' that may be perceived to be beyond the professional boundaries of a dietitian.

There was an association between involvement and confidence, which is consistent with previous findings (Whelan et al. 2008; Oosthuizen 2011). Dietitians who were more confident in undertaking clinical or educational activities relating to genetics and nutritional genomics were more likely to be involved in them, and this relationship is likely to be bidirectional.

Dietitians may avoid involvement in activities where they lack confidence as there is a danger in working beyond competency limits while being involved and therefore experienced in an activity is likely to increase confidence in undertaking it. As confidence grows through education and training, undertaking genetics and nutritional genomics activities may become more frequent. While confidence contributes to competence, the two are not the same. Competence in genetic and nutritional genomic activities may be of greater importance as this describes integrated, holistic attributes required for a task, rather than particular skills in isolation. Additionally, high confidence scores for educational activities made the greatest unique contribution to high confidence scores for clinical activities and vice versa. Interestingly, knowledge was not significantly associated with involvement, despite the previous research 
Table 6 Factors associated with high scores for involvement in undertaking activities related to genetics and nutritional genomics among dietitians
By multivariate linear regression

\begin{tabular}{|c|c|c|c|}
\hline & $\mathrm{B} \pm \mathrm{SE}(95 \% \mathrm{CI}$ for $\mathrm{B})$ & $\beta$ & $p$ value \\
\hline \multicolumn{4}{|l|}{ Model 2: Clinical activities (11 activities) } \\
\hline Years of experience & $0.01 \pm 0.01(-0.01$ to 0.02$)$ & 0.03 & 0.371 \\
\hline $\mathrm{PhD}$ & $-0.11 \pm 0.43(-0.95$ to 0.74$)$ & -0.01 & 0.806 \\
\hline Graduated via a postgraduate degree & $0.08 \pm 0.17(-0.25$ to 0.41$)$ & 0.02 & 0.629 \\
\hline Perceive genetics to be important & $-0.06 \pm 0.41(-0.87$ to 0.75$)$ & -0.01 & 0.887 \\
\hline Employed by the public health service & $0.10 \pm 0.18(-0.26$ to 0.46$)$ & 0.02 & 0.596 \\
\hline Research dietitian & $-0.04 \pm 0.28(-0.60$ to 0.52$)$ & -0.01 & 0.887 \\
\hline Health promotion/public health dietitian & $0.29 \pm 0.23(-0.16$ to 0.74$)$ & 0.05 & 0.199 \\
\hline Food service/industry dietitian & $0.35 \pm 0.35(-0.33$ to 1.03$)$ & 0.04 & 0.306 \\
\hline Media and press dietitian & $0.05 \pm 0.53(-0.98$ to 1.09$)$ & 0.00 & 0.921 \\
\hline Knowledge score & $0.03 \pm 0.03(-0.03$ to 0.08$)$ & 0.04 & 0.347 \\
\hline Clinical confidence score & $0.15 \pm 0.01(0.12$ to 0.17$)$ & 0.55 & $<0.001$ \\
\hline Education confidence score & $-0.15 \pm 0.05(-0.25$ to -0.04$)$ & -0.17 & 0.006 \\
\hline Education involvement score & $1.01 \pm 0.14(0.73$ to 1.29$)$ & 0.31 & $<0.001$ \\
\hline \multicolumn{4}{|l|}{ Model 3: Educational activities (3 activities) } \\
\hline Years of experience & $0.00 \pm 0.00(0.00$ to 0.01$)$ & 0.09 & 0.014 \\
\hline $\mathrm{PhD}$ & $0.13 \pm 0.13(-0.12$ to 0.39$)$ & 0.04 & 0.312 \\
\hline Perceive genetics to be important & $0.25 \pm 0.12(0.01$ to 0.50$)$ & 0.07 & 0.040 \\
\hline Employed by the public health service & $-0.09 \pm 0.06(-0.20$ to 0.02$)$ & -0.06 & 0.100 \\
\hline Clinical dietitian & $-0.19 \pm 0.07(-0.32$ to -0.05$)$ & -0.10 & 0.009 \\
\hline Education dietitian & $0.14 \pm 0.05(0.03$ to 0.24$)$ & 0.09 & 0.010 \\
\hline Research dietitian & $0.02 \pm 0.09(-0.15$ to 0.20$)$ & 0.01 & 0.811 \\
\hline Knowledge score & $-0.00 \pm 0.01(-0.02$ to 0.01$)$ & -0.01 & 0.760 \\
\hline Clinical confidence score & $-0.01 \pm 0.01(-0.02$ to 0.00$)$ & -0.06 & 0.267 \\
\hline Education confidence score & $0.10 \pm 0.02(0.07$ to 0.13$)$ & 0.39 & $<0.001$ \\
\hline Clinical involvement score & $0.09 \pm 0.01(0.07$ to 0.12$)$ & 0.30 & $<0.001$ \\
\hline
\end{tabular}

relating practical and theoretical knowledge of genetics and genetics services with physicians' genetic-based clinical activities (Acton et al. 2000; Hunter et al. 1998).

\section{Other significant factors}

The number of years of experience was significantly associated with dietitians' knowledge, involvement in educational activities and confidence in clinical activities (Tables 5, 6, 7). Notably, knowledge and confidence actually decreased with increasing years of experience, a potential effect of the length of time since formal university education on these topics. However, it is also likely that those with greater years of experience undertook their training when genomics and nutritional genomics were not a focus in dietetics curricula.

Dietitians' perception of the importance of an understanding of genetics to the dietetics profession was positively associated with knowledge and involvement, confirming previous reports in small studies (McCarthy et al. 2008). Those who value genetics may be more likely to seek out information and opportunities to be involved.

\section{Differences over time}

Low levels of knowledge, involvement and confidence in genetics and nutritional genomics have previously been reported, but only in isolated, single-country surveys of $<400$ dietitians (Gilbride and Camp 2004; Whelan et al. 2008). Comparing the performance of UK dietitians in this and a past survey is possible as a similar survey instrument was used (Whelan et al. 2008). In that study, mean total knowledge scores in the UK were $41 \%$ and here were $55.9 \%$. Additionally, in the current study, more dietitians reported involvement in genetics activities and fewer reported 'low' levels of confidence. As improvements over time in dietitians' knowledge, involvement and confidence are observable in the UK, similar changes may have occurred in the US and Australia. However, future studies are required that will measure secular trends, and this research provides the first international data set to compare findings with.

Preparedness of health professionals

The findings that knowledge, involvement and confidence relating to genetics and nutritional genomics are limited 
Table 7 Factors associated with high scores for confidence in undertaking activities related to genetics and nutritional genomics among dietitians
By multivariate linear regression

\begin{tabular}{|c|c|c|c|}
\hline & $\mathrm{B} \pm \mathrm{SE}(95 \% \mathrm{CI}$ for $\mathrm{B})$ & $\beta$ & $p$ value \\
\hline \multicolumn{4}{|l|}{ Model 4: Clinical activities (11 activities) } \\
\hline Years of experience & $-0.05 \pm 0.02(-0.09$ to 0.00$)$ & -0.06 & 0.044 \\
\hline $\mathrm{PhD}$ & $-3.81 \pm 1.22(-6.21$ to -1.41$)$ & -0.09 & 0.002 \\
\hline Graduated via a postgraduate degree & $0.44 \pm 0.48(-0.51$ to 1.38$)$ & 0.03 & 0.362 \\
\hline Perceive genetics to be important & $1.77 \pm 1.16(-0.51$ to 4.06$)$ & 0.04 & 0.128 \\
\hline Employed by the public health service & $-0.71 \pm 0.53(-1.75$ to 0.34$)$ & -0.04 & 0.187 \\
\hline Clinical dietitian & $1.11 \pm 0.71(-0.28$ to 2.50$)$ & 0.05 & 0.116 \\
\hline Research dietitian & $-0.16 \pm 0.84(-1.80$ to 1.49$)$ & -0.01 & 0.853 \\
\hline Health promotion/public health dietitian & $0.95 \pm 0.68(-0.38$ to 2.27$)$ & 0.04 & 0.161 \\
\hline Dietetics manager & $1.27 \pm 0.79(-0.28$ to 2.82$)$ & 0.04 & 0.109 \\
\hline Food service/industry dietitian & $-0.59 \pm 1.00(-2.55$ to 1.38$)$ & -0.02 & 0.558 \\
\hline Media and press dietitian & $4.33 \pm 1.49(1.41$ to 7.25$)$ & 0.08 & 0.004 \\
\hline Knowledge score & $-0.05 \pm 0.08(-0.22$ to 0.11$)$ & -0.02 & 0.508 \\
\hline Education confidence score & $2.12 \pm 0.12(1.89$ to 2.35$)$ & 0.66 & $<0.001$ \\
\hline Clinical involvement score & $1.16 \pm 0.12(0.92-1.39)$ & 0.31 & $<0.001$ \\
\hline Education involvement score & $-0.43 \pm 0.43(-1.27$ to 0.41$)$ & -0.04 & 0.316 \\
\hline \multicolumn{4}{|l|}{ Model 5: Educational activities (3 activities) } \\
\hline Years of experience & $0.01 \pm 0.01(0.00$ to 0.03$)$ & 0.05 & 0.079 \\
\hline $\mathrm{PhD}$ & $1.78 \pm 0.36(1.07$ to 2.49$)$ & 0.14 & $<0.001$ \\
\hline Graduated via a postgraduate degree & $0.17 \pm 0.14(-0.11$ to 0.46$)$ & 0.03 & 0.234 \\
\hline Employed by the public health service & $-0.43 \pm 0.16(-0.74$ to -0.12$)$ & -0.08 & 0.007 \\
\hline Clinical dietitian & $-0.10 \pm-0.20(-0.50$ to 0.30$)$ & -0.01 & 0.624 \\
\hline Education dietitian & $0.39 \pm 0.15(0.10$ to 0.69$)$ & 0.07 & 0.009 \\
\hline Research dietitian & $0.47 \pm 0.25(-0.02$ to 0.96$)$ & 0.05 & 0.059 \\
\hline Food service/industry dietitian & $0.45 \pm 0.30(-0.14$ to 1.04$)$ & 0.04 & 0.133 \\
\hline Knowledge score & $0.08 \pm 0.02(0.04$ to 0.13$)$ & 0.09 & 0.001 \\
\hline Clinical confidence score & $0.19 \pm 0.01(0.17$ to 0.21$)$ & 0.61 & $<0.001$ \\
\hline Clinical involvement score & $-0.11 \pm 0.04(-0.18$ to -0.03$)$ & -0.09 & 0.005 \\
\hline Education involvement score & $0.86 \pm 0.12(0.62$ to 1.10$)$ & 0.23 & $<0.001$ \\
\hline
\end{tabular}

among dietitians mirror results of studies conducted with other non-genetic health professionals such as physicians, nurses, midwives and allied health professionals (Metcalfe et al. 2002; Skirton et al. 2012; Godino and Skirton 2012; Benjamin et al. 2009; Lapham et al. 2000; Long et al. 2001). Efforts to increase the awareness and competence of health professionals in relation to genetics and genomics have been addressed via multiple approaches. Competency guidelines have been developed for health professionals (e.g. NCHPEG 2007; ANA 2011; RCGP 2006) and educational centres and networks have been set up in a number of countries (e.g. National Genetics Education and Development Centre, UK; Genetics/Genomics Competency Centre for Education, US). Strategies for tertiary education and continuing professional development are advancing, with introduction of genetics and genomics into undergraduate curricula and emergence of novel teaching strategies such as digital-based learning (Busstra et al. 2007) and an interdisciplinary approach focusing on lived experience (Kirklin 2003). In the dietetics field, the Academy of
Nutrition and Dietetics has released a proposed position concept on the 'Importance of nutritional genomics in dietetics' (ADA 2010), and tertiary curriculum frameworks in the US and UK have been updated to include genetics and nutritional genomics, respectively (ACEND 2012; BDA 2008). Undoubtedly, further work is still required to prepare dietitians for the nutritional genomic revolution.

Limitations, strengths and opportunities for future research

This survey was conducted with a volunteer sample recruited from three countries. The sampling methodology, response rate and some demographic characteristics differed by country. The survey response rate $(13 \%)$ was poor, which may have been a result of the length of the survey, degree of difficulty and lack of perceived relevance. However, the response rate compares favourably with the only other electronic survey (Oosthuizen 2011) undertaken with dietitians on this topic. On the other hand, 
it was much lower than that achieved in a previous postal survey (McCarthy et al. 2008). Electronic surveys tend to achieve lower response rates than postal surveys, but undoubtedly have a much greater reach (Shih and Fan 2009). Follow-up to determine characteristics of nonresponders was not possible; therefore, the effect of any potential selection bias remains unknown. These limitations result in a lack of generalisability of the findings from this study to the wider dietetics profession.

Knowledge is a notoriously difficult concept to measure. Although this study tested knowledge objectively, it was limited to 16 questions and focused only on the theory of genetics and nutritional genomics and, as such, was not measured exhaustively. There is an opportunity to develop new tools for measuring knowledge that capture the practical and applied aspects of genetics and nutritional genomics. This study did not survey involvement and confidence in genetics and nutritional genomics outside the clinical and educational domains of dietetics. Future research may focus on activities in other areas of dietetic practice (e.g. public health, research and industry) as the application of nutritional genomics increases. The exploratory nature of qualitative research makes it a useful method to thoroughly investigate knowledge, involvement and confidence among dietitians, and the associated determinants, as demonstrated in a recent study ( $\mathrm{Li}$ et al. 2012). Thus, a mixed methods approach to future research may delve deeper into this topic.

The strength of this study is that it reports on the largest international survey of the dietetics profession ever undertaken, encompassing three countries making major contributions to dietetics practice, education and research.

\section{Conclusions}

Scientific and technological advancements have resulted in greater focus on the role genetics and nutritional genomics play in pathogenesis of disease and management. The delivery of genomics focussed health care will require involvement by many professionals, including dietitians. Dietitians' knowledge, involvement and confidence relating to genetics and nutritional genomics were low, and the interaction between these factors was demonstrated. For health care to make the most of these opportunities in genetics and nutritional genomics, improvements in each of these areas are recommended. This international study provides a contribution to enable genetics and nutritional genomics in dietetic practice to be evaluated longitudinally.

Acknowledgments The authors would like to acknowledge the British Dietetic Association (BDA) and the Dietitians Association of Australia (DAA) for assisting with the distribution of the survey.
Thanks are also deserved by Dr Claire Palermo, Stephanie Lawson and Dr Karen Walker (Monash University) for their valuable contributions to the initial development of the project, focus groups and statistical analysis, respectively. Finally, the authors would like to thank the dietitians from the USA, Australia and the UK for participating in this research.

Conflict of interest The authors of this paper; Jorja Collins, Brenda Bertrand, Veronica Hayes, Sherly (Xueyi) Li, Jane Thomas, Helen Truby and Kevin Whelan declare that they have no conflict of interest.

Ethical standard All procedures followed were in accordance with the ethical standards of the responsible committee on human experimentation (institutional) and with the Helsinki Declaration of 1975, as revised in 2000 (5). consent was obtained from all patients for being included in the study.

\section{References}

Accreditation Council for Education in Nutrition and Dietetics of the Academy of Nutrition and Dietetics (ACEND) (2012) ACEND Accreditation Standards for Dietitian Education Programs. Chicago. http://www.eatright.org/ACEND/content.aspx?id=57. Accessed Oct 2011

Acton RT, Burst NM, Casebeer L, Ferguson SM, Greene P, Laird BL, Leviton L (2000) Knowledge, attitudes, and behaviors of Alabama's primary care physicians regarding cancer genetics. Acad Med 75(8):850-852

American Dietetic Association (ADA) (2010) Proposed position concept: Importance of nutritional genomics in dietetics. http:// www.eatright.org/. Accessed Oct 2011

American Nurses Association (ANA) (2011) Essential Genetic and Genomic Competencies for Nurses with Graduate Degrees. http://www.nursingworld.org/MainMenuCategories/EthicsStand ards/Genetics-1/Essential-Genetic-and-Genomic-Competenciesfor-Nurses-With-Graduate-Degrees.pdf. Accessed March 2013

Benjamin C, Anionwu EN, Kristoffersson U, ten Kate LP, Plass AMC, Nippert I, Julian-Reynier C, Harris HJ, Schmidtke J, Challen K, Calefato JM, Waterman C, Powell E, Harris R (2009) Educational priorities and current involvement in genetic practice: a survey of midwives in the Netherlands, UK and Sweden. Midwifery 25(5):483-499

British Dietetic Association (BDA) (2008) Curriculum Framework for the Pre-Registration Education and Training of Dietitians. Birmingham. http://www.bda.uk.com/publications/CurriculumDocument.pdf. Accessed Oct 2011

Busstra MC, Hartog R, Kersten S, Muller M (2007) Design guidelines for the development of digital nutrigenomics learning material for heterogeneous target groups. Adv Physiol Educ 31(1):67-75

Chen LS, Goodson P (2007) Entering the public health genomics era: Why must health educators develop genomic competencies? J Health Educ 38(3):157-165

Cragun DL, Couch SC, Prows CA, Warren NS, Christianson CA (2005) Success of a genetics educational intervention for nursing and dietetic students: a model for incorporating genetics into nursing and allied health curricula. J Allied Health 34(2):90-96

DeBusk RM, Fogarty CP, Ordovas JM, Kornman KS (2005) Nutritional genomics in practice: Where do we begin? J Am Diet Assoc 105(4):589-598

Department of Health (2008) Genetics White Paper. Our inheritance, our future - Realising the potential of genetics in the NHS- 
Progress review. London, HMSO. http://webarchive.national archives.gov.uk/+/www.dh.gov.uk/en/Publichealth/Scientificd evelopmentgeneticsandbioethics/Genetics/DH_084147. Accessed Oct 2011

Edwards PJ, Roberts I, Clarke MJ, Di Guiseppi C, Wentz R, Kwan I, Cooper R, Felix LM, Pratap S (2009) Methods to increase response to postal and electronic questionnaires. Cochrane Database Syst Rev, 2009(3):MR000008

Emery J, Watson E, Rose P, Andermann A (1999) A systematic review of the literature exploring the role of primary care in genetic services. Fam Pract 16(4):426-445

Evans JR, Mathur A (2005) The value of online surveys. Internet Res 15(2):195-219

Ferro WG, Kuo GM, Jenkins JF, Rackover MA (2012) Pharmacist education in the era of genomic medicine. J Am Pharm Assoc 52(5): $113-\mathrm{e} 121$

Gilbride JA, Camp K (2004) Preparation and needs for genetics education in dietetics. Top Clin Nutr 19(4):316-323

Godino L, Skirton H (2012) A systematic review of nurses' knowledge of genetics. J Nurs Educ Pract 2(3):173

Guttmacher AE, Jenkins J, Uhlmann WR (2001) Genomic medicine: Who will practice it? A call to open arms. Am J Med Genet 106(3):216-222

Hunter A, Wright P, Cappelli M, Kasaboski A, Surh L (1998) Physician knowledge and attitudes towards molecular genetic (DNA) testing of their patients. Clin Genet 53(6):447-455

Kirk M, Lea D, Skirton H (2008) Genomic health care: is the future now? Nurs Health Sci 10(2):85-92

Kirklin D (2003) Responding to the implications of the genetics revolution for the education and training of doctors: a medical humanities approach. Med Educ 37:168-173

Kyler P, Thomas MJ (2000) Implications of the human genome project for occupational therapy. OT Practice 5(4):CE-1-CE-8

Lapham EV, Kozma C, Weiss JO, Benkendorf JL, Wilson MA (2000) The gap between practice and genetics education of health professionals: HuGEM survey results. Genet Med 2(4):226-231

Li S, Collins J, Lawson S, Truby H, Whelan K, Thomas J, Palermo C (2012) Is genetics the future? A qualitative exploration of dietitians' engagement with nutritional genomics. Abstract, 16th International Congress of Dietetics Sydney
Long TM, Brady R, Lapham EV (2001) A survey of genetics knowledge of health professionals: implications for physical therapists. Pediatr Phys Ther 13(4):156-163

McCarthy S, Pufulete M, Whelan K (2008) Factors associated with knowledge of genetics and nutritional genomics among dietitians. J Hum Nutr Diet 21(6):547-554

Metcalfe S, Hurworth R, Newstead J, Robins R (2002) Needs assessment study of genetics education for general practitioners in Australia. Genet Med 4(2):71-77

National Coalition for Health Professional Education in Genetics (2001) Recommendations of core competencies in genetics essential for all health professionals. Genet Med 3:155-159

National Coalition for Health Professional Education in Genetics (NCHPEG) (2007) Core competencies in Genetics. 3rd ed. MD, USA. http://www.nchpeg.org/index.php?option=com_content\&view=arti cle\&id=237\&Itemid=84. Accessed March 2013

Oosthuizen L (2011) Aspects of the involvement, confidence and knowledge of South African registered dietitians regarding genetics and nutritional genomics. University of Stellenbosch, Dissertation

Rosen R, Earthman C, Marquart L, Reicks M (2006) Continuing education needs of registered dietitians regarding nutrigenomics. J Am Diet Assoc 106(8):1242-1245

Royal College of General Practitioners (RCGP) (2006) Genetics in Primary Care. London, UK. http://www.rcgp.org.uk/gp-tra ining-and-exams/gp-curriculum-overview/ /media/Files/GP-trai ning-and-exams/Curriculum\%20previous\%20versions $\% 20$ as $\%$ 20at\%20July\%202012/curr_archive_6_Genetics_in_Primary_Care_ v1_0_jan06.ashx. Accessed March 2013

Shih T-H, Fan X (2009) Comparing response rates in e-mail and paper surveys: a meta-analysis. Educ Res Rev 4(1):26-40

Skirton H, O'Connor A, Humphreys A (2012) Nurses' competence in genetics: a mixed method systematic review. J Adv Nurs 68(11):2387-2398

Wellcome Trust Case Control Consortium (2007) Genome-wide association study of 14,000 cases of seven common diseases and 3,000 shared controls. Nature 447:661-678

Whelan K, McCarthy S, Pufulete M (2008) Genetics and diet-gene interactions: involvement, confidence and knowledge of dietitians. Br J Nutr 99(1):23-28 